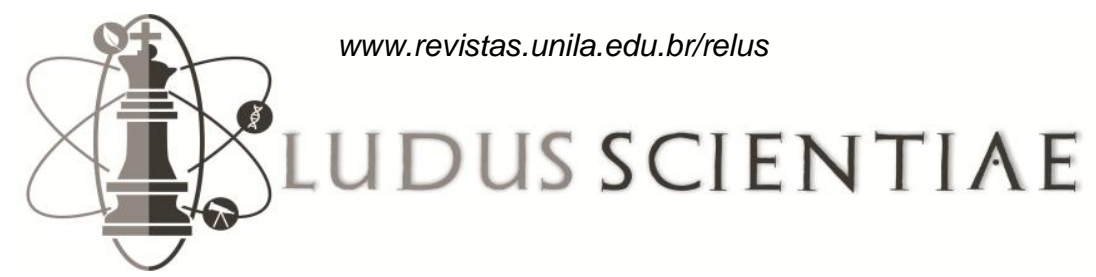

Revista eletrônica Ludus Scientiae - (RELuS) | V. 3, N. 1, Jan./Jul. 2019.

\section{O IMAGINÁRIO DE PROFESSORES DE FÍSICA SOBRE O USO DE JOGOS NO ENSINO DA FÍSICA DE PARTÍCULAS ELEMENTARES}

\author{
The imaginary of physics teachers concerning the use of games in elementary particle \\ physics teaching \\ El imaginario de profesores de fisica sobre el uso de juegos en la enseñanza de la fisica de \\ partículas elementales
}

\begin{abstract}
Resumo
Apresentamos os resultados de um estudo que investigou o imaginário de um grupo de professores que ensinam física acerca do uso de jogos destinados ao ensino da Física de Partículas Elementares. Os dados foram coletados em um curso de formação continuada oferecido para professores em docência escolar da rede pública do estado de São Paulo. Após uma exposição acerca das Partículas Elementares e dos Aceleradores, apresentamos aos professores um conjunto de jogos que abordam assuntos pertencentes a esse tópico, para que jogassem e analisassem as potencialidades e delimitações dos mesmos. Ao final, solicitamos aos professores que respondessem um questionário. As respostas foram analisadas à luz da Análise do Discurso de Michel Pêcheux, especificamente no que diz respeito ao imaginário. Os resultados indicam que o uso de jogos permeia o imaginário dos professores. Para um grupo, eles são recursos lúdicos que ajudam os alunos a memorizarem equações. Para outros, os jogos são recursos potencialmente significativos na aprendizagem de conteúdos, além de auxiliarem no desenvolvimento de atitudes, por exemplo, lidar com regras.
\end{abstract}

Palavras-Chave: Jogos didáticos; Física de Partículas Elementares; Análise do Discurso

\begin{abstract}
We present the results of a study that investigated the imaginary of a group of Physics teachers about the use of educational games focusing on teaching Elementary Particle Physics. Data was collected during a continuing education course offered to teachers who work in public schools in the state of São Paulo. After a presentation about the Elementary Particles and Accelerators, we presented a set of games approaching this subject. The games were played by the teachers and they analyzed the potentialities and delimitations of them. In sequence, we asked the teachers to answer a questionnaire. The given answers were analyzed according to Michel Pêcheux's Discourse Analysis focusing on the imaginary. The results show that the use of games are in the imaginary of the teachers. According to one group, games are playful resources that help students memorize equations. To the others, games are potentially significant resources in learning contents, besides they help to develop attitudes, for example, on how to deal with rules.

Keywords: Educational games; Elementary Particle Physics; Discourse Analysis
\end{abstract}

\section{Resumen}

Presentamos los resultados de un estudio que investigó el imaginario de un grupo de profesores que enseñan física acerca del uso de juegos destinados a la enseñanza de Física de Partículas Elementales. Los datos fueron recolectados en un curso de formación continua ofrecido para profesores en docencia escolar de la red pública del estado de São Paulo. Luego de una exposición acerca de las Partículas Elementales y de los Aceleradores, presentamos a los profesores un conjunto de juegos que abordan asuntos pertenecientes a ese tópico, para que jugasen y analizasen las potencialidades y delimitaciones de los mismos. Al final, solicitamos a los profesores que respondiesen un cuestionario. Las respuestas fueron analizadas a la luz del Análisis del Discurso de Michel Pêcheux, específicamente en lo relacionado al imaginario. Los resultados indican que el uso de juegos permea el imaginario de los profesores. Para un grupo, ellos son recursos lúdicos que ayudan a los alumnos a memorizar ecuaciones. Para otros, los juegos son recursos potencialmente significativos en el aprendizaje de contenidos, además de auxiliar en el desarrollo de actitudes, por ejemplo, lidiar con reglas.

Palabras clave: Juegos didácticos; Física de Partículas Elementales; Análisis del Discurso

\section{AUTOR:}

ORCID 0000-0002-2400-1847

Universidade Estadual Paulista (UNESP)

\section{LEANDRO LONDERO \\ DA SILVA}

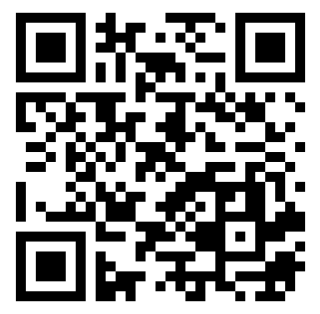

Para citar este artigo:

SILVA, L. L. O imaginário de professores de física sobre o uso de jogos no ensino da física de partículas elementares. Revista Eletrônica Ludus Scientiae, Foz do Iguaçu, v. 03, n. 01, p. 46-68, jan./jul. 2019. 


\section{INTRODUÇÃO}

A necessidade de se ensinar tópicos de Física Moderna e Contemporânea (FMC) na escola básica, para que os alunos sejam capazes de entender, interpretar e desenvolver um senso crítico sobre o novo mundo que os cerca, têm sido apontada por diversos autores (PANTOJA et al., 2011; SILVA e ALMEIDA, 2011; PEREIRA e OSTEMANN, 2009; PENA, 2006; GRECA e MOREIRA, 2001, OSTERMANN e MOREIRA, 200o). Terrazzan $(1992,1994)$ argumentou que a tendência de se atualizar o currículo de Física é justificada pela influência crescente dos conteúdos contemporâneos para o entendimento do mundo criado pelo homem atual, bem como a necessidade de formar um cidadão consciente e participativo que atue nesse mundo.

Mesmo com a clara necessidade de atualização dos currículos escolares, a Física ensinada nas escolas aborda muito pouco os conteúdos de FMC e enfatiza os tópicos da Física Clássica, o que leva a entender que a Física é uma ciência morta, sem avanços ou novas descobertas desde o século XIX. Silva et al. (2013) argumentam que esse panorama descontextualizado contribui para que os estudantes não conheçam a revolução que ocorreu na Física após o ano de 1900 e, assim, não entrem em contato com os parâmetros do desenvolvimento da ciência.

O ensino da Física escolar concentra os conteúdos entre aqueles desenvolvidos entre os séculos XV e XIX, deixando os assuntos pertencentes à FMC para o final do ano letivo, muitas vezes, devido à falta de tempo e/ou preparo dos professores, eles sequer são abordados em sala de aula.

Podemos afirmar que dificilmente toda a programação é cumprida. É comum que os programas mais completos de física do Ensino Médio se reduzam à Cinemática, Leis de Newton, Termologia, Óptica Geométrica, Eletricidade e Circuitos Elétricos Simples. Essa limitação do conteúdo, ao mesmo tempo em que exclui a FMC, reduz discussões acerca da origem da ciência e a maneira como ela se desenvolve. De acordo com Terrazzan (1992), a prática escolar usual exclui tanto o nascimento da ciência como a entendemos a partir da Grécia Antiga, quanto as grandes mudanças no pensamento científico ocorridas na virada do século XIX e as teorias daí decorrentes.

Abordar uma física contemporânea, que se aproxima mais do cotidiano dos alunos, acrescentaria muito no que se refere ao desenvolvimento do senso crítico do estudante, mas também mostraria uma ciência viva e mais atrativa. Como infere Stannard (1990), a Física Moderna é o tópico que mais causa influência nos alunos na escolha da Física como carreira.

Podemos apontar como justificativas para se inserir FMC na escola básica aquelas descritas por Barojas (1988), são elas: a) despertar a curiosidade dos estudantes, e ajudá-los a conhecer a Física como um empreendimento humano e, portanto, mais próxima a eles; b) os estudantes não têm contato com o excitante mundo da pesquisa atual em Física, pois não veem nenhuma Física além de 190o. Essa situação é inaceitável em um século em que ideias revolucionárias mudaram a ciência totalmente; c) é mais divertido para o professor ensinar tópicos que são novos. O entusiasmo pelo ensino deriva do entusiasmo que se tem em relação ao material didático utilizado e de mudanças estimulantes no conteúdo do curso. É importante não desprezar os efeitos que o entusiasmo tem sobre o bom ensino.

Concordamos com as justificativas apontadas por Barojas (1988). No entanto, é importante enfatizar que a primeira justificativa também pode ser alcançada por meio de outros conteúdos conceituais de Física. A inserção da FMC, por si só, não garante que os alunos reconheçam a Física como um empreendimento humano.

Outra justificativa para o estudo da FMC está relacionada com o desenvolvimento da ciência e da tecnologia, que vêm atreladas a diversas pseudociências que, por sua vez, utilizam a ignorância de pessoas leigas para tirar vantagens. O estudo da FMC na escola poderia evitar que a sociedade seja enganada por pseudocientistas, ou seja, charlatões, fazendo os cidadãos questionar as diversas pseudociências que encontramos. 
Torre (1998) também apresenta algumas justificativas para a inserção da FMC no Ensino Médio, entre elas, conectar o estudante à sua própria história, protegê-lo do obscurantismo das pseudociências e das charlatanias pós-modernas e que o aluno possa localizar corretamente o ser humano na escala temporal e espacial da natureza. A FMC possui múltiplas e evidentes consequências tecnológicas, sendo uma parte inseparável da cultura produzida pelo homem.

Pensamos a FMC não pode ser simplesmente inserida no currículo de Física e seguir os mesmos parâmetros e diretrizes dos demais tópicos curriculares. Terrazzan (1992), por exemplo, sugere alguns parâmetros que devem ser seguidos para a elaboração de atividades que contemplam a inserção de assuntos pertencentes à FMC. A especificação do currículo, a necessidade de se privilegiar leis gerais e conceitos fundamentais, exigindo pouco formalismo matemático, a compatibilidade do estudo da Física Clássica e da FMC dentro da mesma programação e a falta de professores preparados para o ensino da Física Moderna são alguns dos aspectos mais relevantes que devem ser considerados no momento de preparação de atividades didáticas.

Pinto (1999) sugere, tanto no que se refere ao ensino da Física Clássica quanto ao da FMC, partirmos do pressuposto de que os aspectos a serem considerados no Ensino Médio devem ser os mais diversos possíveis. Para esse autor, a Física a ser ensinada deve ser apresentada com uma ampla abordagem. O formalismo matemático, a observação, a experimentação, os conceitos, as leis, as teorias, a filosofia, a história, a epistemologia e a tecnologia são exemplos de formas do conhecimento físico com as quais diferentes alunos podem possuir afinidade.

Por outro lado, Terrazzan (1992) infere que o desenvolvimento do ensino da FMC não depende só dos pesquisadores e professores na universidade, deve haver um intercâmbio de informações contínuo entre esses e os professores do Ensino Médio que levarão os conteúdos para as salas de aulas. Esse intercâmbio é essencial para que os professores do Ensino Médio tenham contato e se familiarizem com o conteúdo, além de contribuir com o desenvolvimento do estudo fazendo com que de fato ele chegue às salas de aula. Esse autor ainda completa que, a constatação pura e simples da realidade escolar pode muitas vezes levar-nos a certo ceticismo sobre possibilidades práticas de alteração do quadro da maneira como ele se apresenta.

Concordamos com os apontamentos de Pinto e Zanetic (1999). Para eles, devemos nos atentar as dificuldades atreladas ao ensino da FMC, o formalismo matemático extremamente avançado junto com conceitos novos, que são muito distantes dos estudados na Física Clássica, e a dificuldade de se reproduzir experimentos para exemplificar os tópicos da FMC.

Ostermann e Moreira (200o) apresentam três vertentes representativas de abordagens metodológicas para a introdução de FMC no ensino médio: exploração dos limites dos modelos clássicos; não utilização de referências aos modelos clássicos e; escolha de tópicos essenciais.

Para Gil et al. (1988), autores da primeira vertente, o ensino tradicional da FMC pode gerar diversas concepções alternativas sobre os tópicos estudados. Os autores sugerem, portanto, uma aprendizagem construtivista, de forma que os alunos são postos em situações-problema que explorem os limites da física clássica e forcem de certo modo os alunos a construírem o conhecimento de FMC para solucionar essas situações-problemas.

A segunda vertente segue uma via contrária à primeira. Fischler e Lichtfeldt (1992) acreditam que o ensino de FMC é dificultado pelo frequente uso de analogias com a física clássica. Os autores sugerem, portanto, que o ensino de FMC siga algumas premissas básicas. Os educadores devem evitar relações e referências com a física clássica, introdução do efeito fotoelétrico a partir das características do elétron e não do fóton, interpretação estatística do fenômeno deve ser usada e descrições dualistas devem ser evitadas, relação de incerteza de Heisenberg deve ser introduzida no começo (e formulada para objetos quânticos) e a exclusão do modelo de Bohr no tratamento do átomo de hidrogênio. 
A terceira vertente é atribuída a Arons (1990), da Universidade de Washington, Estados Unidos. $\mathrm{O}$ autor argumenta que somente alguns tópicos da FMC devem ser abordados no Ensino Médio. Para ele, os alunos devem aprender somente conceitos que os tornem capazes de identificar e entender os elétrons, fótons e a estrutura atômica e que o ensino da FMC deve se sustentar na física clássica para sua abordagem.

Além dessas vertentes, encontramos na literatura, outras sugestões para o ensino da FMC. Terrazzan (1994), por exemplo, infere que cada tópico abordado exige uma metodologia diferente e cabe ao professor escolher o método que melhor se adapte à sua aula e seus alunos. Mesmo dando essa abertura ao professor, esse autor destaca que o ensino de FMC deve destacar a História e Filosofia da Ciência.

Por sua vez, Pinto e Zanetic (1999) relatam uma experiência educacional desenvolvida em uma escola pública, na qual diferentes formas de expressão humana como a arte, a música e a pintura compuseram uma estratégia de ensino que permitiu apresentar a Física como cultura, procurando despertar o interesse de um número maior de estudantes.

Mais recentemente, Kikuchi et al. (2013) constataram que a inserção da FMC está acontecendo a partir de diferentes tópicos e abordagens, porém de maneira pontual, o que vai ao encontro dos resultados apontados anteriormente por Pereira e Ostermann (2009).

Em nosso estudo, estamos interessados, particularmente, no ensino da Física de Partículas Elementares (FPE). Perante isso, julgamos significativo apresentar, na próxima seção, uma breve introdução da FPE.

\section{A FÍSICA DAS PARTÍCULAS ELEMENTARES: UMA BREVE INTRODUÇÃO}

O homem sempre buscou entender a composição da matéria, do que ela é constituída e como ela é formada. O conceito de átomo, a menor fração de matéria possível, algo indivisível, foi desenvolvido já na Grécia Antiga. Desde então, busca-se a compreensão desse fragmento, porém, somente vinte e cinco séculos após o desenvolvimento desse conceito é que ele foi quebrado por J. J. Thonsom, físico inglês que descobriu pela primeira vez uma porção da matéria menor que o átomo. Tal descoberta foi a primeira partícula elementar: o elétron.

Em seguida, diversas outras partículas foram descobertas e muitas delas foram erroneamente classificadas como partículas elementares, já que a tecnologia da época não permitia que cientistas identificassem a estrutura mais íntima da matéria e dificultava a compreensão do conceito teórico de partícula elementar. Foi necessário pouco mais de um século para que os cientistas descobrissem e classificassem todas as partículas elementares, que hoje são classificas segundo o Modelo Padrão e divididas em três subgrupos: Quarks, Léptons e Bósons (também conhecidos como partículas mediadoras).

As partículas foram separadas e classificadas de acordo com critérios que identificam os tipos de interação às quais elas são submetidas, sua massa ou energia, seu spin, dentre outros fatores utilizados para classificá-las como pertencentes a uma das três famílias de partículas elementares.

A palavra Lépton vem do grego "leve" e essas partículas são classificadas dessa forma por não interagirem por meio da força nuclear forte, ou seja, elas interagem nuclearmente apenas por meio da força nuclear fraca. Existem três tipos ou sabores de Léptons que possuem cargas e uma partícula neutra com as mesmas características de massa, energia e spin está relacionada a cada um deles. São eles: o Elétron e o Neutrino do Elétron, o Múon e o Neutrino do Múon, o Tau e o Neutrino do Tau.

Os Quarks são as únicas partículas elementares que interagem por meio da força nuclear forte e são responsáveis pela composição de quase toda a matéria existente. Ao interagirem, elas constituem 
partículas maiores, como o próton e o nêutron, que são a base da composição dos átomos. Assim como os Léptons, existem seis tipos ou sabores de quarks, são eles: Up, Down, Charm, Strange, Bottom e Top.

Já os Bósons, ou partículas mediadoras, são responsáveis pela interação entre todas as partículas do universo, sendo que cada um dos Bósons é responsável por "transmitir" umas das forças elementares da natureza. O Glúon é responsável pela "transmissão" da força nuclear forte, o Fóton, partícula que representa a forma corpuscular da luz, é responsável pela força de interação eletromagnética e os Bósons $\mathrm{W}$ e Z são responsáveis por toda interação nuclear fraca. Teoricamente, existiria, ainda, uma partícula chamada Gráviton, que seria responsável pelas interações gravitacionais, porém, essa partícula não foi detectada até o presente momento. Entre os Bósons, existe ainda mais uma partícula que não está relacionada a nenhuma força elementar da natureza, o Bóson de Higgs, conhecido por dar origem à massa das outras partículas elementares.

Após determinadas suas características, as partículas são classificadas segundo o Modelo Padrão, divididas em duas partes, a dos Férmions, dividida em duas subfamílias, Léptons e Quarks, e a família dos Bósons, como pode ser observado na figura 1.

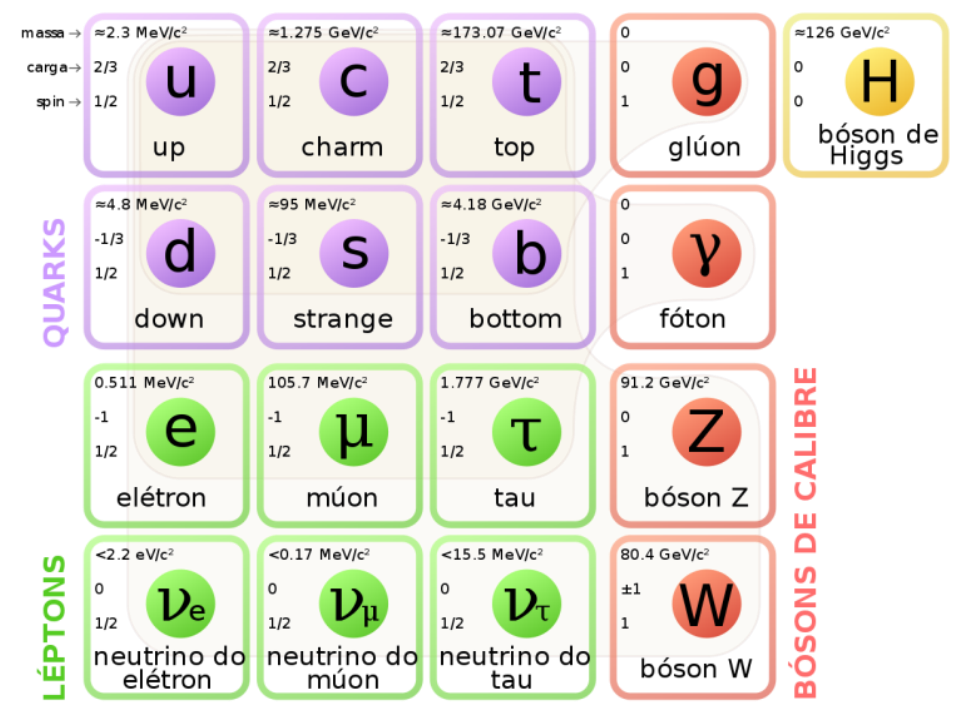

Figura 1: Modelo Padrão de partículas Elementares. Disponível em: https://pt.wikipedia.org/wiki/Modelo padrão\#/media/File:Standard Model of Elementary Particles-ptbr.svg.

Se pararmos para pensar nas possibilidades de inserção da FPE no Ensino Médio encontramos diversos recursos didáticos, entre os quais podemos citar os textos de divulgação científica, os mapas conceituais e os jogos didáticos. Estamos interessados, especificamente, no uso de jogos regrados e digitais para o ensino da FPE. Na próxima sessão apresentamos nossas considerações a respeito do uso de jogos no ensino.

\section{O USO DE JOGOS NO ENSINO E NA APRENDIZAGEM}

Ao discutirmos a formação de professores, entram em pauta os modelos pedagógicos que focam apenas na transmissão do conhecimento para o aluno, colocando o professor no centro, como único protagonista do desenvolvimento do aluno. A imagem de escola que vemos é aquela de uma tradicional, com aulas prioritariamente expositivas, alunos em filas organizadas e o protagonismo nos professores.

A diversidade de alunos na sala de aula mostra a necessidade de inovação nas práticas escolares e alternativas às aulas tradicionais. Para Pinto (2009), a variedade de instrumentos pedagógicos está, dentre outras coisas, em explorar as diferentes características de aprendizagem de cada indivíduo. 
O uso de práticas alternativas às aulas tradicionais, como uso de jogos, não só respeita a diversidade presente na sala de aula, como coloca o aluno como protagonista do seu próprio desenvolvimento. Murcia (2008) argumenta que o ensino deve favorecer uma participação mais ativa por parte da criança no processo educativo. Deve-se estimular as atividades lúdicas como meio pedagógico que, junto com outras atividades, como artísticas e musicais, ajudam a enriquecer a personalidade criadora, necessária para enfrentar os desafios da vida.

Podemos dizer que os jogos trazem diversos benefícios para o desenvolvimento do aluno, uma vez que trabalham com aspectos cognitivos, afetivos e físico-motor. Quando exposto as diversas situações presentes nos jogos, os alunos são levados a, de certa maneira, trabalharem em grupo, desenvolvendo relações interpessoais.

Para Friedmann (1996) os jogos assumem importante papel nos intercâmbios afetivos, envolvendo a criança com seus pares e também com adultos significativos (pais e professores). Para o autor, os jogos são como uma 'janela' para a vida emocional da criança.

O uso de jogos varia conforme o desenvolvimento cognitivo da criança. Piaget (1971) separa os jogos em três categorias, jogos de exercício, jogos simbólicos e jogos de regras. Nos primeiros anos de vida, a criança ainda não se desenvolveu cognitivamente, portanto os jogos de exercício, que desenvolvem habilidades sócio-motoras e estão totalmente ligados ao prazer, são recomendados Já na fase pré-operatória, os jogos simbólicos proporcionam à criança, além do prazer a linguagem, o prazer da realidade que o cerca. No período operatório concreto, passamos a utilizar os jogos de regras, que consiste em relacionar os jogos de exercícios com os jogos simbólicos e, ainda, acrescentar regras a eles, dessa maneira a criança aprende a seguir regras e desenvolve seu relacionamento coletivo.

Piaget (1971) completa que as regras se desenvolvem na criança em três etapas. Nos anos iniciais, as crianças não são capazes de compreender ou seguir regras de caráteres coletivos, chamada de anomia. Na segunda etapa, até os dez anos, as regras são impostas nas crianças, de maneira que elas as sigam por medo e respeito. As regras permanecem assim externas ao sujeito, essa é chamada de heteronomia. Na terceira etapa, chamada de autonomia, as crianças seguem as regras do jogo e passam a desenvolver novas regras, dessa maneira as regras estão internalizadas no sujeito.

Silveira e Barone (1998) defende o uso de jogos educativos, argumentando que, quando são empregados de maneira correta, podem auxiliar em diversos aspectos. Segundo o autor, os jogos podem desenvolver a autoconfiança e aumentar a motivação dos alunos, quando usados de maneira prática ao conhecimento aprendido. Ainda, os jogos podem ser aplicados de maneira a apresentar informações factuais e desenvolver destreza e competências nos alunos.

Quando usados como ferramentas de ensino, os jogos colocam os alunos em situações nas quais eles são obrigados a utilizar os conhecimentos adquiridos nas situações de aprendizagem, de uma maneira lúdica e divertida, tornando a construção do conhecimento mais divertida e natural para o aluno.

Para Fialho (2008) os jogos com finalidades pedagógicas promovem situações de ensino e aprendizagem, as quais podem aumentar a construção do conhecimento. Nesse sentido, o uso de jogos pode colocar os alunos em diversas situações-problemas, mostrando não só como resolver o problema, mas também que existem diferentes maneiras para solucioná-lo. Além disso, o uso de jogos pode levar o aluno a desenvolver a agilidade de raciocínio e a concentração, melhorando as relações do aluno com as situações reais do meio cultural na qual está inserido.

Kishimoto (1994) destaca o caráter social dos jogos ao argumentar que eles são resultados de um sistema linguístico que funciona dentro de um contexto social. Para Macedo, Petty e Passos (2005) a perspectiva do jogar relaciona-se com a apropriação da estrutura das possíveis implicações e 
tematizações. Sendo assim, para os autores não é somente jogar que importa, mas principalmente refletir sobre as decorrências da ação de jogar.

A interação entre os alunos, proposta pelos jogos, pode desenvolver discussões que levam os alunos a compreenderem melhor os conteúdos trabalhados. A linguagem semelhante dos alunos faz com que a comunicação entre eles seja facilitada. Pinto (2009) esclarece que certos aspectos da aprendizagem não ocorrem, porque o professor não se faz claro para o aluno. Quando os alunos discutem e trabalham em grupo, a linguagem semelhante utilizada por eles facilita no processo de ensino e aprendizagem.

A escolha dos jogos a serem utilizados é uma tarefa importante na ação docente, já que eles devem auxiliar no processo de ensino e aprendizagem. Os jogos escolhidos não podem conter somente entretenimento lúdico, eles devem conter conteúdo educativo e, para o professor, devem estar claros os objetivos que pretendem atingir com o uso deles, caso contrário a atividade perderá o caráter educativo e se tornará apenas uma atividade lúdica. No entanto, não descartamos a importância do aspecto lúdico no processo de ensino e aprendizagem.

Para Pinto (2009) é necessário que o jogo não perca, em sua prática, o aspecto educativo em prol apenas do lúdico, mantendo assim, o objetivo central, focado na relação ensino e aprendizagem. Dessa maneira, o aluno poderá compreender a relação entre a atividade desenvolvida e o conhecimento adquirido.

Destacamos que o professor não se deve limitar a utilizar jogos que já estão prontos. A possibilidade de desenvolver seu próprio jogo ou modificar os jogos existentes é real. O professor deve ser capaz de elaborar atividades que contemplem o uso de jogos e adaptar esses ao seu estilo de aula, a sua classe e ao conteúdo que deseja apresentar. Para isso, segundo Pereira et al. (2009), um professor apresenta plenas condições de desenvolver um jogo para implementar em sala de aula, especificamente, para um conteúdo abordado e para as suas necessidades. O autor cita que o professor deve dominar os referenciais teóricos do conteúdo implícito no jogo, ser capaz de relacioná-los a situações concretas e atuais, pesquisar e avaliar recursos didáticos favoráveis às situações de ensino e aprendizagem. Perante isso, o professor será capaz de desenvolver ou adaptar um jogo para as suas aulas.

Na pesquisa aqui relatada, estamos interessados no uso de jogos para o ensino de conteúdos de física, em partículas, para os assuntos pertencentes ao tópico de Partículas Elementares. Nas próximas seções detalharemos os objetivos de nossa pesquisa e os procedimentos metodológicos.

\section{OBJETIVOS, PROBLEMA, QUESTÕES NORTEADORAS E JUSTIFICATIVA}

Nosso estudo parte das considerações mencionadas anteriormente e da constatação da ausência, na literatura consultada, de um estudo que apresente as potencialidades e delimitações do uso de jogos, no ensino de assuntos de FMC, em particular no ensino da FPE, na visão de professores que ensinam física. Perante isso, objetivamos conhecer e compreender o imaginário de um grupo de professores que ensinam física acerca do uso de jogos regrados e digitais destinados ao ensino da Física de Partículas Elementares. Procuramos respostas para o seguinte problema:

Como os professores interpretam o uso de jogos didáticos no processo de ensino e aprendizagem no contexto de aulas de Física no Ensino Médio que abordam a Física de Partículas Elementares?

Das possíveis questões que seriam relevantes responder, as seguintes nos parecem significativas e são propostas para este estudo: 1) Qual a importância do ensino de Física de Partícula Elementares no Ensino Médio no imaginário dos professores investigados? 2) Que papel os professores investigados atribuem aos jogos didáticos destinados ao ensino da Física e, em particular, ao jogos para o ensino da FPE? 3) Quais características os professores citam como mais pertinentes para que os jogos se constituam como um recurso eficaz no ensino da FPE? 
Nossa pesquisa pode ser justificada pelo fato de que, em geral, os professores de física possuem pouco ou nenhum contato com jogos didáticos durante a formação inicial e, portanto, pouco utilizam desse recurso em sala de aula. Perante isso, investigar o imaginário de professores pode ser um passo inicial no avanço das discussões acerca do uso de jogos no ensino da física. Além disso, o tópico de FPE possui formalismo matemático muito avançado e de difícil compreensão e, por consequência, o uso de jogos justifica-se pela familiaridade dos alunos com esse tipo de atividade e pelo potencial didático que os mesmos apresentam.

\section{PROCEDIMENTOS METODOLÓGICOS}

O desenvolvimento da pesquisa ocorreu com a colaboração de 31 professores da rede pública da Diretoria de Ensino da região de São José do Rio Preto/SP. A pesquisa foi realizada durante uma orientação técnica (OT) intitulada "Física de Partículas Elementares: Aspectos Teóricos e Pedagógicos", publicada página 54 do Diário Oficial do Estado de São Paulo do dia 27 de maio de 2017, promovida pela Equipe de Educação em Física "Susana Lehrer de Souza Barros", com a finalidade de promover a formação continuada desses professores em serviço.

A orientação técnica solicitada pela Diretoria de Ensino ocorreu em dois ambientes do Laboratório do Curso de Pedagogia do Instituto de Biociências, Letras e Ciências Exatas, pertencente à Universidade Estadual Paulista "Júlio de Mesquita Filho" - campus de São José do Rio Preto, e foi dividida em dois dias, de forma que metade dos professores participasse no primeiro dia e metade no segundo. Com um menor número de professores em cada dia tornou-se mais fácil mediar os conteúdos desejados e sanar as dúvidas recorrentes dos professores.

Em um primeiro momento, realizamos uma exposição acerca da FPE com a finalidade de relembrar e introduzir conceitos pertencentes a esse tópico. A exposição teve como foco o Modelo Padrão de Partículas Elementares e os Aceleradores de Partículas. Em um segundo momento, os professores foram divididos em grupos para jogarem um conjunto de jogos que apresentamos a eles com o intuito de avaliarem a potencialidades e delimitações de uso deles para o ensino da FPE.

Os jogos utilizados na OT foram obtidos a partir de levantamentos prévios que realizamos na internet, cujo objetivo foi o de identificarmos jogos didáticos que estão disponíveis para download e que são destinados ao ensino da FPE. Além disso, os jogos foram selecionados a partir de nossa experiência no "International Masterclass Hands on Particle Physics", realizado no Instituto de Física Teórica (IFT) da Unesp, campus São Paulo. Os jogos disponibilizados aos professores foram: Pôquer de Partículas; Quark-Tzee; Estrutura do Átomo de Hélio. Durante a orientação, afirmávamos o papel do professor como mediador na implementação dos jogos em salas de aulas.

O Pôquer das Partículas ou Quark Card Game foi desenvolvido pelo Prof. Hélio Takai para ensinar aos estudantes o conceito de Modelo Padrão - a existência de quarks, subestruturas de mésons e baryons, decaimento de partículas e o conceito de carga de cor. Ele segue as mesmas regras do pôquer convencional, mas no lugar dos naipes do baralho convencional são colocadas as partículas elementares. Esse jogo pode ser obtido no site International Particle Physics Outreach Group (http://ippog.org).

Cada baralho possui 52 cartas, com quarks e leptons, e quatro quarks Selvagens. Esses podem ser usados em números variados de zero a 4 . Na figura 2 reproduzimos 4 cartas para exemplificação ao leitor. 

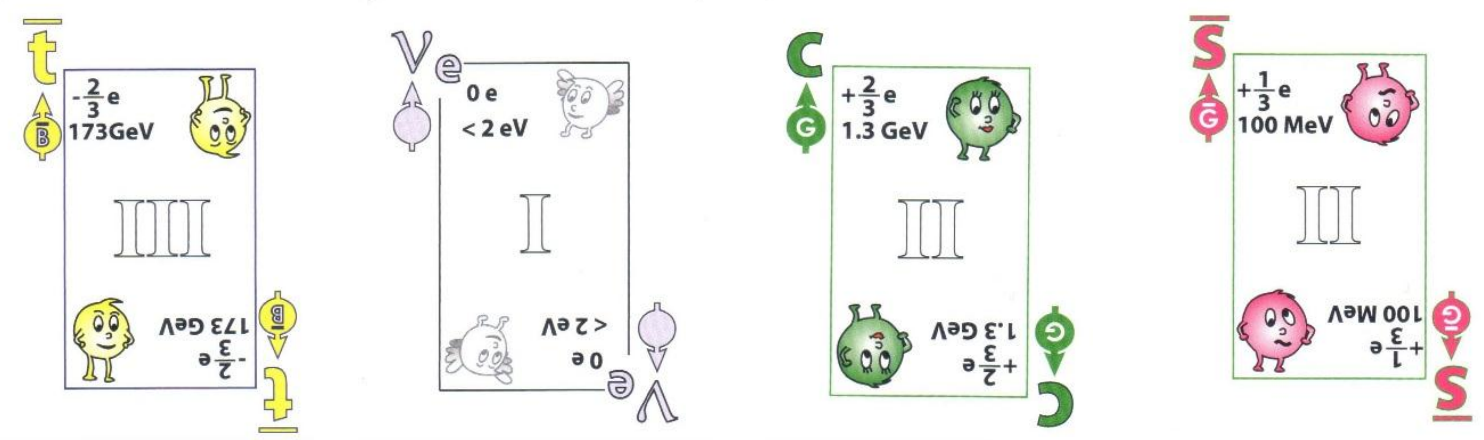

Figura 2: Exemplos de cartas do Pôquer das Partículas. Disponível em: http://ippog.org/resources/2011/quark-card-game.

Os jogadores recebem duas cartas cada um, e o mediador do jogo coloca cinco cartas sobre a mesa, revelando-as em sequência, em três rodadas. Na primeira rodada, são reveladas três cartas e na segunda e terceira serão reveladas uma. Os jogadores devem fazer combinações com as cartas em suas mãos e as cartas que estão na mesa para formar diferentes tipos de partículas, levando em consideração não só a partícula em si, mas utilizando as relações entre as partículas e as antipartículas e as diferentes cores, devido às forças de interação nuclear forte. Com base na tabela energética reproduzida no anexo 1 , vencerá o jogo quem conseguir montar as partículas com maior energia ou quem montar o maior número de partículas.

Por sua vez, o Quark-Tzee ou General das Partículas é um jogo de dados que segue as regras do General. Esse jogo também foi proposto pelo Prof. Hélio Takai e, assim como o Pôquer das Partículas, pode ser obtido no site do International Particle Physics Outreach Group. Ele é composto por seis dados, cada um possui uma cor ou anticor fundamental (figura 3) e em cada uma das faces está estampados o símbolo que representa uma partícula Quark, de maneira semelhante ao reproduzido na figura 4.
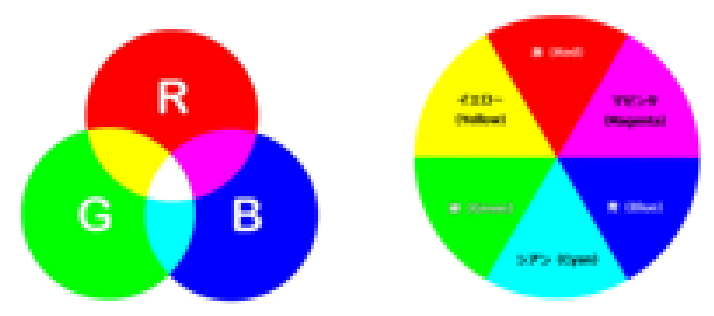

Figura 3: Cores e anticores das Partículas Elementares.

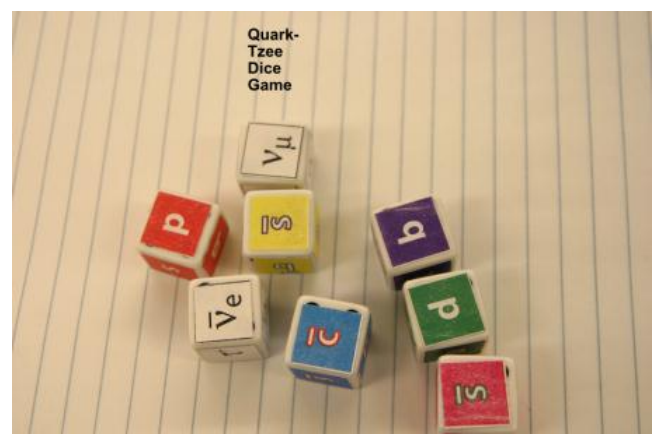

Figura 4: Dados do jogo. Disponível em: http://ippog.org/resources/2011/quark-tzee-dice-game.

O jogo consiste em cada jogador lançar os seis dados de uma só vez e com os resultados obtidos montar diferentes tipos de partículas. Para a montagem, os jogadores devem levar em consideração a 
interação entre as partículas e as antipartículas, além de observar as cores de cada dado, que representam a força de interação nuclear forte.

A ideia é começar com os seis dados e poder lançá-los até três vezes. Em cada lançamento, o jogador mantém os dados que considerar melhor para formar certas partículas. O primeiro lance, com todos os dados, é usado para criar mésons e barions, tantos quanto desejar. No segundo lance, somente aqueles dados que não foram usados no primeiro lance, e assim por diante. Assim, seguindo a tabela energética presente no anexo 1, vencerá o jogador que conseguir montar as partículas com maior valor energético ou o jogador que conseguir montar o maior número de partículas.

Já o terceiro jogo, intitulado "A Estrutura do Átomo de Hélio", os jogadores têm como objetivo construir um átomo de Hélio. Para isso, cada jogador receberá quatro cartas (figura 5). As cartas possuem imagens do quark up e do quark down junto com suas respectivas cargas e de diferentes cores (verde, vermelho e azul), além de elétrons e pósitrons. Todas as outras cartas ficarão juntas entre os jogadores.

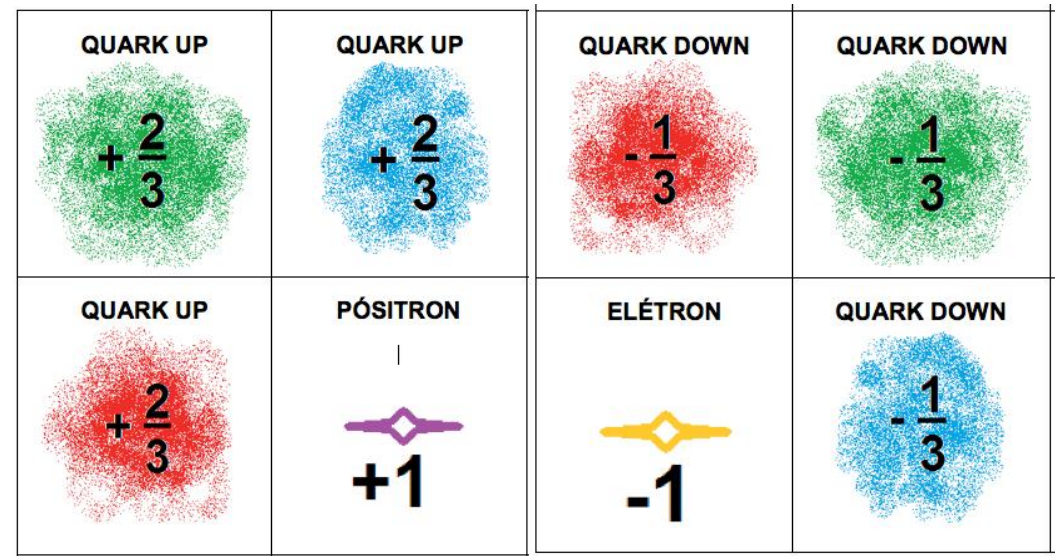

Figura 5: Cartas do jogo "A Estrutura do Átomo de Hélio.

Para montar o átomo de Hélio, os jogadores devem construir, com as cartas que possuem, dois prótons (constituído de dois quarks up e um quark down) e dois nêutrons (constituído de um quark up e dois quarks down), não respectivamente nessa ordem, além de ligar dois elétrons quando o núcleo do átomo estiver pronto.

O primeiro jogador de cada turno deve comprar uma carta do monte e descartar uma carta que não seja favorável para o seu jogo. O jogador seguinte pode escolher se comprará uma carta do monte ou se pegará a carta que foi descartada pelo jogador anterior. Caso o jogador junte ao mesmo tempo um elétron e um pósitron na sua mão, as partículas entrarão em reação e explodirão. O jogador deve descartar as duas cartas e comprar mais duas cartas do monte.

Se o jogador tiver as cartas certas para montar um próton ou um nêutron ele deve fazê-lo imediatamente, baixando as cartas na mesa para que todos possam ver e pegar outras três cartas no monte, isso se repetirá a cada vez que o jogador conseguir montar umas das partículas constituintes do átomo de Hélio. Será vencedor o primeiro jogador que conseguir montar o núcleo do átomo de Hidrogênio e ligar os dois elétrons a ele.

Mais ao final, os professores foram levamos para um laboratório de informática, no qual foram apresentados para o último jogo que utilizaríamos, o qual é nomeado SPRACE GAME 2.0, sendo esse o único jogo digital trabalhado com os professores.

O SPRACE GAME 2.0 é um jogo de caráter virtual, para computadores, desenvolvido pelo Instituto de Física Teórica (IFT) da Unesp, que proporciona aos jogadores aprender os conceitos básicos sobre a composição da matéria por meio da tarefa de construir partículas subatômicas a partir 
de seus constituintes mais fundamentais. O Sprace pode ser obtido por meio de download no seguinte link: https://sprace.org.br/index.php/education-outreach/sprace-game/.

No jogo, o jogador assume o papel de um cientista que é encolhido junto com sua nave e seu laboratório a proporções subatômicas com a finalidade de construir moléculas de água para colonizar o planeta Marte. No processo de encolhimento, todos os dados sobre as partículas são perdidos e cabe ao jogador recuperá-los. Usando o mouse como cursor, o jogador deve usar os canhões da nave para capturar e levar as partículas até seu laboratório para que sejam novamente classificadas.

O jogo é dividido em quatro diferentes missões. A primeira Missão tem como objetivo capturar e classificar todas as partículas da família dos Léptons, no menu do jogo os jogadores podem consultar características como carga, massa, energia e spin de cada um dos Léptons. A segunda missão tem como objetivo capturar e classificar partículas da família dos Mésons. Após classificá-las, os jogadores podem consultar suas características no menu do jogo e ainda analisar a composição dessas partículas. A terceira missão do jogo tem como objetivo capturar e classificar partículas da família dos Bárions, incluindo os Prótons e os Nêutrons. Nessa missão os jogadores também podem consultar e analisar as características e a formação de cada uma das partículas. A quarta e última missão tem como objetivo construir átomos de hidrogênio e oxigênio para criar moléculas de água para que a raça humana seja capaz de colonizar o planeta Marte. Para isso os jogadores devem usar a função "desacelerar o tempo" no laboratório e "pegar" quarks de outras partículas para formar Prótons e Nêutrons e por fim o núcleo de átomos de Hidrogênio e Oxigênio. Na figura 6 é possível observar uma das telas do SPRACE.

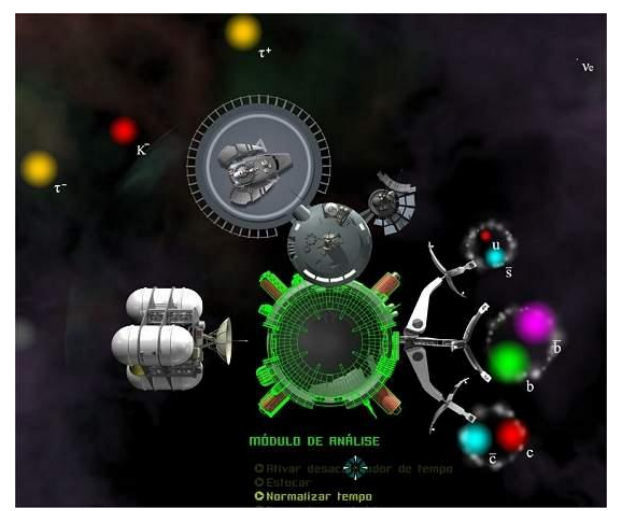

Figura 6: Laboratório analisando as partículas durante a desaceleração do tempo no jogo SPRACE GAME 2.0.

O SPRACE foi implementado de maneira que os professores estivessem livres para atingir os objetivos do jogo, os quais são apresentados pelo próprio jogo. Os instrutores da OT (autores deste trabalho) auxiliavam os professores que estavam com dificuldades e explicavam como deveriam mediá-lo durante o seu uso em sala de aula.

Ao final do dia, solicitamos aos professores que respondessem um questionário composto com um total de nove perguntas, são elas: 1) Você já trabalhou com algum tipo de jogo educativo (tabuleiros, perguntas e respostas, cartas etc.)? Em caso afirmativo, diga qual(is) assunto(s) esses jogos abordaram; 2) Para você, o uso de jogos educativos pode ajudar no desempenho escolar dos alunos? Em caso positivo, explicar como eles podem contribuir no desempenho dos alunos e ajudar esses a construírem conceitos?; 3) O que você considera que aprendeu em nossa Orientação Técnica (OT)?; 4) Os jogos trabalhados ajudaram na sua compreensão da Física de Partículas Elementares? Em que medida? Justifique.; 5) Quais os pontos positivos você destacaria nos jogos utilizados na nossa OT? a) Pôquer das Partículas; b) General das Partículas; c) A Estrutura do Âtomo de Hélio e; d) SPRACE; 6) Quais os pontos negativos você destacaria nos jogos utilizados na nossa OT? a) Pôquer das Partículas; b) General das Partículas; c) A Estrutura do Átomo de Hélio e; d) SPRACE; 7) Quais sugestões você daria para o uso de jogos no ensino da Física e, em especial, para o uso dos jogos utilizados em nossa 
OT?; 8) Os jogos utilizados em nossa OT podem ser utilizados, com alunos do Ensino Médio, para o ensino da Física de Partículas Elementares? Eles ajudariam os alunos no entendimento da Física de Partículas Elementares? Comente?; 9) Qual seria o papel do professor, em sala de aula, durante o uso dos jogos?

As respostas foram transcritas, tabuladas em quadros específicos elaborados para nosso estudo e analisadas à luz do referencial teórico de análise que utilizamos, o qual será explicitado na sequência.

\section{O TRATAMENTO DOS DADOS: O REFERENCIAL TEÓRICO DE ANÁLISE}

Podemos conceituar o discurso como um efeito de sentido entre dois locutores. Dessa maneira a linguagem torna-se algo particular, uma constituição do sujeito e à produção dos sentidos. O discurso aparece como um interlocutor da história do sujeito, pois sem história não há sujeito. Segundo Orlandi (1994), é a inscrição da história na língua que faz com que ela signifique.

O estudo dessa relação entre o discurso, a linguagem e o contexto é chamado de Análise do Discurso (AD). Para Orlandi (1994), a AD se constitui no espaço disciplinar que põe em relação à Linguística com as Ciências Sociais. A AD não vai juntar simplesmente os dois campos do conhecimento, mas trata essa separação como material de contradição. Orlandi (1994) esclarece que a $\mathrm{AD}$ vai trabalhar essa separação necessária, isto é, ela vai estabelecer sua prática na relação de contradição entre esses diferentes saberes. Essa separação proporciona à AD seu objeto de estudo próprio, o discurso, e é nesse que encontramos a relação entre a linguagem e a ideologia.

Para a AD o sujeito se constitui a partir da sua história. Perante isso, a $\mathrm{AD}$ exclui qualquer tipo de sujeito que se constitua sem uma história. $\mathrm{Na} A D$, o sentido atribuído a um fenômeno/conceito/objeto não é diferente, ele se constitui por meio da história. A AD descarta a ideia de que existe um sentido único do qual derivam os outros sentidos, como também descarta que o sentido pode ser qualquer, uma vez que nesses casos há uma exclusão da história. Segundo Orlandi (1994), a AD considera que o sentido não está já fixado a priori, como essência das palavras, nem tampouco pode ser qualquer um: há determinação histórica do sentido.

Orlandi (1994) esclarece que o discurso é definido como processo social cuja especificidade está em que sua materialidade é linguística. A relação com a história nos mostra que a relação entre linguagem e sociedade gera o discurso, sendo assim o caráter social e o linguístico constroem em conjunto o discurso.

O sujeito, portanto, se constitui a partir da sua relação com o mundo e com a linguística, essa relação dá origem à ideologia. Para Orlandi (1994), a ideologia é como o imaginário que medeia a relação do sujeito com suas condições de existência. A autora pontua que não existe relação termo-a-termo entre as coisas com a linguagem, incompatíveis em sua natureza própria. Portanto, por sempre trabalharmos esse tipo de relação, ocorre a diferenciação entre as noções de social, de histórico, de ideológico e de linguagem.

No âmbito do social, o imaginário criado a partir das relações sociais sobrepõe os traços ideológicos e cria as imagens que aparecem no discurso, como a imagem que se faz da mãe, de um professor etc. O imaginário, portanto, funciona como um interlocutor entre a linguagem e o mundo. Orlandi (1994) argumenta que não existe relação direta entre a linguagem e o mundo. A relação não é direta, mas funciona como se fosse, por causa do imaginário. Por sua vez, Barbier (1994) considera o imaginário como a capacidade elementar e irredutível de evocar uma imagem, a faculdade originária de afirmar ou se dar, sob a forma de representação, uma coisa e uma relação que não existe.

Recordemos que o foco de nossa pesquisa é saber que imaginário a respeito dos jogos materializase no discurso dos professores(as), considerando o funcionamento da língua na história e, também, que o sentido sempre pode ser outro, como destaca Orlandi (2012). Assim, nosso dispositivo metodológico incide 
no discurso presente nas respostas dadas pelos professores(as) às perguntas do questionário, com foco na representação imaginária dos sujeitos colaboradores em relação ao uso dos jogos.

Nossos colaboradores são sujeitos que assumem uma posição. Perante isso, analisamos os discursos que se fazem presentes nas respostas, buscando saber que imaginário a respeito do uso de jogos se materializa nos discursos, destacando as memórias e o saberes que sustentam seus discursos na constituição do imaginário.

\section{OS DISCURSOS E OS IMAGINÁRIOS DOS PROFESSORES}

Tendo em vista o conjunto de respostas obtidas, apresentamos e comentamos alguns discursos que nos parecem mais significativos de serem expostos aos leitores.

Primeiramente, destacamos que a tabulação das respostas revelou que, dos 31 professores(as), somente o6 declararam nunca ter utilizado jogos em sala de aula. Essa constatação permite inferir que o uso de jogos parece ser um recurso frequente entre a maior parte dos professores, principalmente em relação aos jogos matemáticos. Porém, muitos dos professores declaram não compreender o potencial didático dos jogos e os utilizam apenas para desenvolver o aspecto lúdico no aluno, como observado por meio da leitura dos seguintes discursos:

"Sim, já trabalhei, porém não abordava com procedimentos metodológicos como demonstrados nesta OT." (Professor 3)

"Sim, nas aulas de matemática. Utilizamos mancala, batalha naval, zig zag, resto, entre outros." (Professor 5)

"Sim, em matemática traverse, zique zigue, mancala e outros." (Professor 8)

"Sim, jogos matemáticos: traverse, zigue-zague". (Professor 9)

"Envolvendo Física nunca trabalhei jogos educativos, houve uma vez que consegui trabalhar com caça palavras". (Professor 13)

"Xadrez, damas, resta um, trilha entre outros jogos matemáticos". (Professor 25)

O primeiro discurso evidencia que o professor usa os jogos sem nenhum embasamento teórico ou metodológico, ou seja, sem nenhuma organização prévia de uso, ou até faz uso de maneira improvisada. Talvez essa seja a prática de muitos professores quando do uso de jogos ou de outros recursos de ensino. No entanto, podemos supor que os professores apresentam tais comportamentos em virtude de suas reais condições de trabalho ou pela formação inicial deficitária que obtiveram.

Nos discursos dos Professores 5, 8, 9 e 25 observamos menções explicitas aos jogos matemáticos. Isso ocorre em virtude da formação inicial dos sujeitos participantes da OT, os quais são majoritariamente formados em matemática, mas possuem habilitação para física.

Ao serem questionados se o uso de jogos pode ajudar no desempenho escolar dos alunos e como eles contribuem nesse desempenho e ajudam na formação de conceitos, os professores mencionaram:

"Sim, pois faz com que o aluno tenha uma concentração melhor, melhore o raciocínio" (Professor 2)

"Sim, existe o desenvolvimento do raciocínio lógico e a melhora na concentração na hora do jogo. Logo pode melhorar a concentração nas aulas." (Professor 25) 
"Acredito que o uso de jogos venha a contribuir com o desempenho dos alunos, pois tratando-se de uma atividade lúdica, é mais divertido o entendimento dos conceitos abordados no jogo." (Professor 4)

"Sim porque de forma lúdica trabalha conceitos, estratégias e lógica, desenvolvendo o raciocínio e facilitando o aprendizado.” (Professor 9)

"Com certeza os jogos educativos ajudam no desempenho dos alunos, promovem um aprendizado lúdico, os alunos aprendem conceitos complicados sem perceber!" (Professor 13)

"Acredito que sim, pois é uma forma de mostrar o conceito com prática visual." (Professor 17)

Nos discursos acima é recorrente o uso do termo Lúdico. Vale a pena recordar que a palavra Lúdico é um adjetivo masculino e tem sua origem do latim ludos que significa jogos, brinquedo e divertimento. Pensamos que os docentes devem ter claro que os jogos não são simples "distrações" para entreter os alunos, ao contrário, eles são recursos que ocupam lugar de extraordinária importância na educação formal. Concordamos com Santos (2000) ao argumentar que:

Educadores e pais necessitam ter clareza quanto aos brinquedos, brincadeiras e/ou jogos que são necessários para as crianças, sabendo que eles trazem enormes contribuições ao desenvolvimento da habilidade de aprender e pensar. No jogo, ela está livre para explorar, brincar e/ou jogar com seus próprios ritmos, para autocontrolar suas atividades, muitas vezes é reforçada com respostas imediatas de sucesso ou encorajada tentar novamente, se da primeira alternativa não obteve o resultado esperado (p. 166).

Almeida (1995), por sua vez, nos esclarece que:

A palavra ludicidade tem sua origem na palavra latina "ludus" que quer dizer "jogo". Se achasse confinada a sua origem, o termo lúdico estaria se referindo apenas ao jogo, ao brincar, ao movimento espontâneo, mas passou a ser reconhecido como traço essencialmente psicofisiológico, ou seja, uma necessidade básica da personalidade do corpo e da mente no comportamento humano, as implicações das necessidades lúdicas extrapolaram as demarcações do brincar espontâneo de modo que a definição deixou de ser o simples sinônimo de jogo. O lúdico faz parte das atividades essenciais da dinâmica humana, trabalhando com a cultura corporal, movimento e expressão (p. $56)$.

Os discursos, acima reproduzidos, parecem indicar que para os professores os jogos podem ajudar no desempenho escolar dos alunos, em especial no desenvolvimento da concentração, do raciocínio e da lógica.

Por sua vez, há professores que manifestam um imaginário no qual o jogo é tido apenas como um auxiliar para as aulas de física, um recurso que ajuda os alunos a memorizarem e decorarem equações, como podemos observar nos discursos reproduzidos abaixo.

"Sim, principalmente para memorização e assimilação de regras e processos." (Professor 7)

"Sim, a guardar conceitos e fórmulas." (Professor 20)

"Acredito que toda ferramenta utilizada para uma aprendizagem mais efetiva é válida, pensando nisso os jogos pedagógicos seriam muito bem-vindos. Os jogos poderiam ser utilizados como um memorizador facilitando a aprendizagem." (Professor 21) 
Pensamos que atividades lúdicas não levam à memorização mais fácil do assunto tratado, mas induzem os alunos a raciocinar, refletir, pensar etc. Uma possível justificativa para os discursos dos professores é a formação a qual estiveram expostos na graduação e ao tipo de ensino que praticam nas escolas, uma vez que eles são, em sua maioria, formados em matemática e recorrem a um ensino matematizado da física.

Por outro lado, há um grupo de professores que vislumbram os jogos como um recurso com grande potencial didático para o ensino de física e, em especial, das partículas elementares. Para esse grupo, os jogos fazem os alunos interagirem entre si e se envolverem com o conteúdo abordado. Ainda, os jogos possibilitam a assimilação dos conteúdos, o que parece ser mais difícil de ocorrer em aulas expositivas, teóricas e/ou de quadro negro. Além disso, os jogos possibilitam, no imaginário dos professores, a visualização da teoria. As falas a seguir são exemplos representativos desse imaginário.

"Sim, tomando como base a interação entre os professores, e a metodologia utilizada para compreensão dos fenômenos das partículas atômicas, acredito que a interação entre os alunos corresponderá." (Professor 3)

"Sim. Pois, assimilando as regras do jogo, automaticamente os alunos assimilarão os conteúdos da disciplina, que se passados através de aula expositiva e/ou quadro-negro ficariam menos estimulantes." (Professor 6)

"Sim, trabalhar de forma diferenciada ajuda o aluno a aprender o conteúdo com mais envolvimento, observação, parceria e respeito." (Professor 8)

"Sim, pois através de jogos é possível trabalhar de forma mais leve e descontraída, tornando maior a interação dos alunos com o conteúdo, posso citar ainda, que o aluno assimilará e fixará o conteúdo através da repetição do jogo, sem que este se canse." (Professor 10)

"Sim, os alunos ficam atentos às regras, se envolvem mais com o tema abordado, uma vez que, o desenvolvimento da atividade por vezes depende de instruções relacionadas ao tema." (Professor 22)

"Sim, uma vez que alguns assuntos trabalhados de forma lúdica chamariam mais atenção dos alunos fugindo assim das aulas teóricas muitas vezes maçantes. São metodologias diferentes que devem sim ser usadas visando sempre a maior compreensão dos alunos." (Professor 24)

"Sim ajuda, pois fica mais fácil visualizar a teoria e sua função na prática, para que o educando relacione a forma útil dos conteúdos em sua prática." (Professor 16)

Há, ainda, professores que relacionam os jogos com a aprendizagem de conteúdos de natureza atitudinal, entre os quais foram citados: respeitar regras e cumprir metas preestabelecidas. Esse é o caso observado no discurso do professor 23, reproduzido abaixo.

"Ajuda muito, desde seguir algumas regras para iniciar o jogo, a vontade de querer ganhar o jogo faz com que eles se dediquem mais para aprenderem o conteúdo.” (Professor 23)

De maneira geral, os professores vislumbram os jogos didáticos como um recurso com grande potencial didático, seja de maneira mais simplista, para desenvolver o lúdico e prender a atenção, a uma maneira mais aprofundada, analisando as competências que os jogos desenvolvem se utilizados de maneira apropriada, contribuindo não só para o desenvolvimento lúdico e intelectual, como também para o desenvolvimento social do aluno.

Consideramos importante conhecer o imaginário dos professores em relação ao uso de jogos no ensino de conteúdos de FMC, em especial da Física das Partículas Elementares. As respostas obtidas 
permitem inferir que os professores compreendem a importância do ensino de tópicos de FMC, em especial da FPE. Para eles esse tópico pode desenvolver habilidades e competências que serão utilizadas pelo aluno no seu cotidiano. Especificamente, sobre a importância de se ensinar FPR, os professores responderam:

"É importante ressaltar o ensino de física de partículas no ensino médio para os alunos compreenderem não só a existência da física clássica, mas também da moderna nos dias de hoje para compreender temas atuais." (Professor 1)

"O conhecimento científico é extremamente importante na formação do ser, superando o senso comum com o intuito de somar à visão de mundo do aluno melhorando sua compreensão do mesmo. O ensino de física de partículas ajuda a compreender melhor a formação da matéria, o cerne da realidade do nosso universo." (Professor 4)

"É a ciência "viva", bem perto da época em que ele vive fazendo com que o interesse aumente, pois ele pode ser um dos cientistas que dará continuidade aos estudos daquele ou outro fenômeno. Vai entender um pouco mais o mundo que vive." (Professor 5)

"Física de partículas é de extrema importância, apesar de ser um assunto bastante abstrato, é algo que aproxima o aluno da ciência, podemos fazer a ligação com a área tecnológica da atualidade, provoca curiosidade para procurar mais notícias e quem sabe se interessam em seguir a área acadêmica." (Professor 13)

"Devido ao avanço da ciência este assunto se torna cada vez mais comum em meios digitais e midiáticos, mostrando a necessidade de o aluno ter este tipo de conhecimento para o entendimento desse avanço." (Professor 10)

"A sua importância é mostrar o que se usa na vida e o que se ensina na escola, pois muitos alunos acham que os conceitos não servem para serem usados.” (Professor 17)

No discurso do Professor 1 percebemos a preocupação dele em colocar os alunos em contato com as produções mais recentes da física. Essa preocupação vai ao encontro das justificativas apresentadas por pesquisadores da área de ensino de física para a inserção de assuntos de FMC na escola média. Um exemplo é a justificativa apresentada por Ostermann et al. (1998). Para esses autores uma justificativa para o ensino de FMC é:

“...estabelecer o contato dos alunos com as ideias revolucionárias que mudaram totalmente a Ciência do século XX, pois para os alunos a Física é um conjunto de conhecimentos que se acabou antes do início do século XX." (p. 270)

Já o discurso do Professor 4 parece indicar que, para ele, o ensino da FPE permitiria confrontar o conhecimento científico com o conhecimento de senso comum. A esse respeito Germano e Feitosa (2013) esclarecem que:

Naturalmente, professores e divulgadores das ciências, se deparam com os saberes prévios e as concepções espontâneas de seus interlocutores. Saberes cotidianos e de senso comum que, nem sempre, concordam com as explicações e conclusões científicas. (p. 724)

Assim, cabe ao professor fazer a mediação entre esses conhecimentos, respeitando as concepções manifestadas pelos alunos.

No discurso do Professor 5 e 10 evidenciamos novamente a preocupação em colocar o aluno em contato com as produções mais recentes da física, podendo "atrair jovens para a carreira científica, futuros pesquisadores, professores” (OSTERMANN et al., 1998). 
Por sua vez, o Professor 13 justifica o ensino da FPE pela presença dela nos meios de comunicação, o que poder possibilitar ao aluno interpretar as informações obtidas por meio desses mecanismos de comunicação.

Em síntese, os discursos dos professores parecem indicar que no imaginário deles o ensino de Física de Partículas Elementares apresenta uma "ciência nova", que está em desenvolvimento, contribuindo para que os alunos abandonem a concepção da Física como uma "ciência morta" e passem a se interessar mais por ela, pois estudam conteúdos que constantemente estão em contato no seu cotidiano e no seu universo vivencial. O contato com o desconhecido, com o "novo", também funciona como um atrativo para os jovens estudantes interessados na ciência.

Adentramos no questionamento das potencialidades e delimitações dos jogos utilizado na OT na visão dos professores. Quando questionados em relação aos jogos apresentados e como eles podem ajudar na compreensão da FPE, os professores responderam:

"Sim, a ajuda foi muito significativa. O principal motivo foi compreender assuntos de forma lúdica." (Professor 3)

"Sim, pois as regras e elementos dos jogos tornam esse conhecimento mais fácil de ser absorvido." (Professor 4)

"Foi no jogo de pôquer que compreendi a interação das partículas e antipartículas com as cores)." (Professor 5)

"Sim. Reafirmo que além de ser importante saber como funciona a física quântica, tem igual importância assimilar bem os nomes das partículas para não se tornar muito desgastante seu estudo. E os jogos cumprem esse papel.” (Professor 6)

"Sim, pois através dos jogos tornou-se mais fácil o entendimento da interação entre as partículas." (Professor 10)

"Os jogos me ajudaram muito a entender a formação de Mésons e Bárions, e acredito que será altamente esclarecedor para os alunos." (Professor 13)

"Sim, pois os jogos abordam conceitos que se devem entender para desenvolvimento do jogo, além de abordar de forma lúdica conceitos abstratos de difícil compreensão." (Professor 17)

"Sim. Excelente para fixação das diversas "propriedades" como: cores e nomes das partículas. Também foi bom ouvir falar um mais sobre novidades como o bóson de Higgs." (Professor 20)

"Sim. Os jogos foram bastante atrativos porque facilitaram a minha compreensão do tema, pois sou professor de matemática." (Professor 26)

"Sim, ajudou bastante pois é uma maneira lúdica e assim podemos entender melhor a estrutura da física." (Professor 31)

"A possibilidade de jogar a qualquer hora sem depender de mais colegas, desde que haja um computador." (Professor 22)

O discurso do Professor 4 parece indicar que as características dos jogos, regras e elementos, possibilitaram uma melhor compreensão da FPF. Já para o Professor 5 cita um dos jogos e a contribuição do mesmo para o entendimento da interação das partículas e antipartículas com as cores. De maneira semelhante, o Professor 10 faz referência aos jogos no "entendimento da interação entre as partículas". 
Durante a implementação dos jogos e com as respostas obtidas no questionário, foi possível evidenciar que os jogos ajudaram na compressão de diversos aspectos, entre os quais podemos citar a formação de Mésons e Bárions, como apontou o Professor 13, e as cores, nomes das partículas e o bóson de Higgs, como explicitou o Professor 20.

É possível hipotetizar que a OT talvez tenha sido mais significativa para os professores com formação em matemática, constatação que pode ser inferida a partir do discurso do Professor 26. A maneira lúdica de representar os conceitos abstratos, somado aos conceitos presentes em cada um dos jogos, fez com que os tópicos abordados na OT se tornassem mais fáceis para os professores que possuíam pouco ou nenhum conhecimento da FPE, e serviu de reforço para aqueles que já possuíam conhecimento sobre o assunto.

Um ponto destacado repetidas vezes foi o da interação entre os professores durante a realização dos jogos. Com isso, a compreensão dos tópicos abordados ficou mais fácil, fluída e divertida. Consideramos que, quando os jogos forem implementados em sala de aula, esse fator de interação entre os alunos poderá acelerar o processo de aprendizagem dos tópicos ensinados.

Contudo, uma preocupação recorrente observada nas produções dos professores é a falta de tempo nas salas de aulas para a implementação dos jogos, uma vez que o uso deles poderá demandar calma para a execução das jogadas. Os discursos dos Professores 18 e 22 são manifestações dessa preocupação.

"Fator tempo é complicado, organizar sala, disciplina, organizar os grupos, tirar dúvidas pontuais individuais de membros de cada grupo. Sendo só o professor, alguns teriam de esperar muito tempo até atende-lo e o aluno perderia o interesse." (Professor 18)

"Sim, podem ser usados e acredito que ajudaria no entendimento dos fenômenos. Mas há um problema que é o tempo. Os jogos são demorados e as aulas de física do ensino médio público é insuficiente para o próprio conteúdo." (Professor 22)

Pensamos que os jogos propostos não despendem tempo significativo para a execução deles. Por outro lado, defendemos o resultado positivo que os alunos terão após a realização das atividades com os jogos, ou seja, os conhecimentos adquiridos, as habilidades e competências formadas.

Para finalizar, consideramos significativo tecer comentários do imaginário dos professores em relação ao papel que eles devem desempenhar durante uma atividade com uso de jogos. Pensamos que o uso de jogos didáticos não depende apenas de uma implementação simplória da atividade. $\mathrm{O}$ professor deve estar atento ao desenvolver a atividade e ao caminho que os alunos estão tomando para desenvolver os conceitos apresentados. As falas abaixo são exemplos representativos do imaginário dos professores quanto ao papel do professor durante uma aula com uso de jogos.

"O professor durante a aplicação dos jogos tem papel fundamental no acompanhamento dos alunos para eventuais dúvidas.” (Professor 1)

"O professor deverá agir como mediador durante alguns dos jogos, mas em outros pode agir como concorrente dos alunos, tornando a aula mais dinâmica e desafiadora para os alunos." (Professor 10)

"Meu papel é o de mediador, levando o aluno a relacionar a teoria com a prática." (Professor 16)

"Inicialmente como mediador de regras/conflitos, mas principalmente de fazer comentários que relacione as combinações para formação das partículas." (Professor 20)

Os discursos parecem indicar que os professores atribuem a si e o papel de mediadores do conhecimento. Grigoletto (2005) esclarece que: 
Partindo do conceito de formações imaginárias, cunhado por Pêcheux (1969), podemos dizer que as imagens que os interlocutores de um discurso atribuem a si e ao outro são determinadas por lugares empíricos/institucionais, construídos no interior de uma formação social. Assim, a imagem do jornalista, por exemplo, já está determinada pelo lugar empírico a ele atribuído por uma determinada formação social. (p. 4)

Nesse sentido, podemos supor que as imagens que os professores atribuem a si e aos colegas são determinadas pelas próprias instituições escolares, imagens que são construídas no interior de uma formação social.

Concordamos com Xavier (2017) ao inferir que "[...] ao mediar as situações de ensino, o professor se coloca entre o aluno e a aprendizagem. A primeira condição para que isso aconteça é a quebra do paradigma do professor como detentor de todo o saber. É necessário, portanto, despir-se do antigo papel e confiar na nova roupagem".

Bulgraen (2010), ao tecer comentários sobre o papel do professor e sua mediação nos processos de elaboração do conhecimento, esclarece que:

Portanto, a ação pedagógica no processo de ensino consiste, basicamente, na "prática social". De modo que, inicialmente cabe ao educador, mediar conhecimentos historicamente acumulados bem como os conhecimentos atuais, possibilitando, ao fim de todo o processo, que o educando tenha a capacidade de reelaborar o conhecimento e de expressar uma compreensão da prática em termos tão elaborados quanto era possível ao educador. Percebe-se então, que tal prática social só pôde ser alcançada através de uma ação pedagógica mediadora e problematizadora dos conteúdos sistematizados, das vivências dos alunos e dos acontecimentos da sociedade atual. Assim sendo, na relação de ensino estabelecida na sala de aula, o professor precisa ter o entendimento de que ensinar não é simplesmente transferir conhecimento, mas, ao contrário, é possibilitar ao aluno momentos de reelaboração do saber dividido, permitindo o seu acesso critico a esses saberes e contribuindo para sua atuação como ser ativo e crítico no processo histórico-cultural da sociedade. De fato, este é o verdadeiro papel do professor mediador que almeja através da sua ação pedagógica ensinar os conhecimentos construídos e elaborados pela humanidade ao longo da história e assim contribuir na formação de uma sociedade pensante. (p. 37)

Os discursos proferidos parecem indicar que os professores compreendem sua ação pedagógica como mediadora e problematizadora dos conteúdos sistematizados. Eles parecem ter claro que nesse tipo de atividade o protagonismo está no aluno e não no professor, o qual tem o papel de mediar o conhecimento, direcionar os questionamentos pontuais e sanar as dúvidas que aparecem durante a implementação dos jogos. Algumas vezes os professores podem aparecer como um competidor e participarem, junto com os alunos, da atividade. Ao se posicionarem como mediadores do conhecimento, os professores compreendem seu papel não mais como detentores de todo o saber, mas como facilitadores do processo de aprendizagem, fazendo perguntas e considerando as experiências prévias dos alunos. Mediar o conhecimento é, portanto, criar pontes entre o conhecimento prévio dos alunos e os conhecimentos científicos que estão sendo estudados.

Por outro lado, identificamos discursos nos quais é possível constatar que a ideia de aulas tradicionais, como único meio eficiente, ainda está muito presente no imaginário dos professores. Parece que para esses, qualquer tipo de atividade lúdica ou que se apresente como diferente das aulas expositivas são meros recursos auxiliares, não sendo possível o completo aprendizado dos conteúdos sem as aulas centradas nas explicações verbais do professor. Os discursos reproduzidos a seguir são exemplos típicos deste imaginário.

"No final, obrigatoriamente deve dar uma aula a moda antiga, explicando mesmo, aprofundando e sintetizando, pois que agora eles têm a familiaridade de algo tão 
abstrato e invisível. Não pode parar em joguinhos, isso é uma apresentação, uma isca motivacional. Necessita de um teórico mais fundamentado." (Professor 7)

"Mediador, porém, essa mediação dever vir após aulas expositivas com explicações do modelo padrão." (Professor 24)

Nos discursos do Professor 7 e do 24 é possível identificar um imaginário no qual os jogos não são percebidos como um elemento de aprendizagem. Por vezes, há professores que se referem aos jogos de maneira pejorativa, por meio do uso, em seus discursos, de termos como "joguinhos". É importante nesses casos analisarmos com maior grau de profundidade quem é o sujeito do discurso e "quem" ou "o que" o levou a esse discurso, suas condições de produção e seu contexto histórico e social. Percebemos com isso a necessidade de que os agentes públicos invistam na formação continuada de seus professores, o que pode ocorrer em parceria com as instituições de nível superior.

\section{CONSIDERAÇÕES FINAIS}

Nosso estudo procurou conhecer e compreender o imaginário de um grupo de professores que ensinam física acerca do uso de jogos destinados ao ensino da Física de Partículas Elementares, a partir da participação deles em um curso de formação continuada.

Os discursos dos professores, obtidos por meio das respostas dadas às perguntas de um questionário, indicam que o uso de jogos permeia o imaginário dos professores. Para um grupo, eles são recursos lúdicos que ajudam os alunos a memorizarem equações. Para outros, os jogos são recursos potencialmente significativos na aprendizagem de conteúdos, além de auxiliarem no desenvolvimento de atitudes, por exemplo, lidar com regras.

Antes das atividades os professores, em sua maioria, mostravam não possuir as habilidades e os conhecimentos necessários para a implementação de jogos em sala de aula, bem como o desconhecimento, por parte de alguns, de conceitos pertencentes ao tópico de Física de Partículas Elementares. Após a implementação, percebemos que avanços significativos que dizem respeito ao melhor entendimento do assunto e das contribuições dos jogos para o ensino da física. Fato comprovado por meio dos discursos dos professores que foram reproduzidos ao longo da apresentação dos resultados. Perante isso, avaliamos positivamente a OT oferecida aos professores, uma vez que eles passaram a manifestar atitudes positivas com relação à importância de realizarem atividades diferentes daquelas executadas em aulas comumente intituladas de tradicionais.

Pensamos que o uso de jogos não é o suficiente para mudar o quadro do ensino da Física Moderna e Contemporânea no Ensino Médio. Contudo, eles aparecem com um possível caminho para o ensino da Física de Partículas Elementares, possibilitando a formação de conceitos e a construção de habilidades e competências, bem como de procedimentos e atitudes.

A título de finalização, destacamos a importância da parceria entre as universidades e os sistemas de ensino, ou seja, as escolas, para que possamos dialogar e diagnosticar os problemas/as dificuldades a serem superadas e construirmos, juntos, as soluções para elas.

\section{AGRADECIMENTOS}

Ao Conselho Nacional de Desenvolvimento Científico e Tecnológico (CNPq), pelo apoio financeiro (Processo $n^{\circ}$ 402596/2016-1), e ao bolsista João Vitor Ribeiro de Souza, pelo apoio na realização da Orientação Técnica.

\section{REFERÊNCIAS}


ALMEIDA, P. N. Educação Lúdica: técnicas e jogos pedagógicos. São Paulo, SP: Loyola, 1995.

ARONS, A. B. A guide to introductory physics teaching. New York: John Wiley, 1990.

BARBIER, R. Sobre o imaginário. Em Aberto, Brasília, v. 14, n. 61, p. 15-23, 1994.

BAROJAS, J. Cooperative networks in physics education. New York: American Institute of Physics, 1988.

BULGRAEN, V. C. O papel do professor e sua mediação nos processos de elaboração do conhecimento. Revista Conteúdo, v. 1, n. 4, p. 30-38, 2010.

FIALHO, N. N. Os jogos didáticos como ferramenta de ensino. In: CONGRESSO NACIONAL DE EDUCAÇÃO / III CONGRESSO IBERO-AMERICANO SOBRE VIOLÊNCIA NAS ESCOLAS, 8/3, 2008. Curitiba, PR. Anais... Curitiba, PR: Champagnat, 2008.

FISCHLER, H.; LICHTFELDT, M. Modern physics and students' conceptions. International Journal of Science Education, v. 14, n. 2, p. 181-190, 1992.

FRIEDMANN, A. Brincar: crescer e aprender: o resgate do jogo infantil. São Paulo, SP: Moderna, 1996.

GERMANO, M. G.; FEITOSA, S. S. Ciência e senso comum: concepções de professores universitários de física. Investigação em Ensino de Ciências, v. 18, n. 03, p. 723-735, 2013.

GIL, D. P.; SENENT, F.; SOLBES, J. Análisis critico de la introducción de la física moderna en la enseñanza media. Revista de Enseñanza de la Física, v. 2, n. 1, p. 16-21, 1988.

GRECA, I. M.; MOREIRA, M. A. Uma revisão da literatura sobre estudos relativos ao ensino da mecânica quântica introdutória. Investigações em Ensino de Ciências, v. 6, n. 1, p. 29-56, 2001.

GRIGOLETTO, E. Do lugar social ao discursivo: o imbricamento de diferentes posições sujeito. In: SEMINÁRIO DE ESTUDOS EM ANÁLISE DO DISCURSO UFRGS, 2005. Porto Alegre, RS. Anais eletrônicos... Porto Alegre, RS: UFRGS, 2005, p. 154-164. Disponível em:

<www.ufrgs.br/analisedodiscurso/anaisdosead/.../EvandraGrigoletto.pdf>. Acesso em: 18 mar. 2019.

KISHIMOTO, T. M. O jogo e a educação infantil. São Paulo, SP: Pioneira, 1994.

MURCIA, J. A. M. Aprendizagem através do jogo. Porto Alegre, RS: Artmed, 2005.

ORLANDI, E. P. Discurso, imaginário social e conhecimento. Em Aberto, v. 14, n. 61, 1994.

. Análise de Discurso. Campinas, SP: Pontes, 2012.

OSTERMANN, F.; FERREIRA, L. M.; CAVALCANTI, C. J. H. Tópicos de física contemporânea no ensino médio: um texto para professores sobre supercondutividade. Revista Brasileira de Ensino de Física, v. 20, n. 3, p. 270-288, 1998.

OSTERMANN, F.; MOREIRA, M. A. Uma revisão bibliográfica sobre a área de pesquisa "Física Moderna e Contemporânea no Ensino Médio". Investigação em Ensino de Ciências, v. 05, n. o1, p. 23-48, 2000.

PANTOJA, G. C. F.; MOREIRA, M. A.; HERSCOVITZ, V. E. Uma revisão da literatura sobre a pesquisa em ensino de Mecânica Quântica no período de 1999 a 2009. Revista Brasileira de Ensino de Ciência e Tecnologia. v. 4, n. 3, p. 1-34, 2011.

PENA, F. L. A. Por que, nós professores de física do ensino médio, devemos inserir tópicos e ideias de física moderna e contemporânea na sala de aula? Revista Brasileira de Ensino de Física, v. 28, n. 1, p. 1-2, 2006.

PEREIRA, A. P.; OSTERMANN, F. Sobre o ensino de física moderna e contemporânea: uma revisão da produção acadêmica recente. Investigações em ensino de Ciências, v. 14, n. 3, p. 393-420, 2009. 
PEREIRA, R. F.; FUSINATO, P. A.; NEVES, M. C. D. Desenvolvendo um jogo de tabuleiro para o ensino de Física. In: ENCONTRO NACIONAL DE PESQUISA EM EDUCAÇÃO EM CIÊNCIAS, 7, 2009. Florianópolis, SC. Anais... Florianópolis, SC: ABRAPEC, 2009.

PINTO, A. C.; ZANETIC, J. É possível levar a Física Quântica para o ensino médio? Caderno Catarinense de Ensino de Física, v. 16, n. 1, p. 7-34, abr. 1999.

PIAGET, J. A formação do símbolo na criança. Rio de Janeiro, RJ: Zahar, 1971.

PINTO, L. T. O uso dos jogos didáticos no ensino de ciências no primeiro segmento do ensino fundamental da rede municipal pública de Duque de Caxias. 2009. Dissertação (Mestrado) - Programa de Pós-Graduação em ensino de Ciências, Instituto Federal de Educação, Ciência e Tecnologia, Nilópolis, 2009.

SANTOS, S. M. P. (Org). Brinquedoteca: a criança, o adulto e o lúdico. Rio de Janeiro, RJ: Vozes, 2000.

SILVEIRA, S. R.; BARONE, D. A. C. Jogos educativos computadorizados utilizando a abordagem de algoritmos genéticos. In: CONGRESSO DA REDE IBEROAMERICANA DE INFORMÁTICA NA EDUCAÇÃO, 1998. Brasília, DF. Anais... , Brasília, DF: RIBIE, 1998.

SILVA, A. C.; ALMEIDA, M. J. P. M. Física Quântica no ensino médio: o que dizem as pesquisas. Caderno Brasileiro de Ensino de Física, v. 28, n. 3, p. 624-652, 2011.

SILVA, J. R. N.; ARENGHI, L. E. B.; LINO, A. Porque inserir física moderna e contemporânea no ensino médio? Uma revisão das justificativas dos trabalhos acadêmicos. Revista Brasileira de Ensino de Ciências e

Tecnologia, v. 6, n. 1, 2013.

STANNARD, R. Modern physics for the young. Physics Education, v. 25, n. 3, p. 133, 1990.

TERRAZZAN, E. A. A inserção da física moderna e contemporânea no ensino de física na escola de $2^{\circ}$ grau. Caderno Catarinense de Ensino de Física, v. 9, n. 3, p. 209-214, 1992.

TERRAZZAN, E. A. Perspectivas para a inserção de física moderna na escola média. 1994. Tese (Doutorado em Educação) - Programa de Pós-graduação em Educação, Universidade de São Paulo, São Paulo, 1994 .

TORRE, A. C. de la. Reflexiones sobre la enseñanza de la física moderna. Educación en Ciências, v. 12, n. 4, p. 70-71, 1998.

XAVIER, C. A importância do papel do professor como mediador. Estadão, São Paulo, 31 out. 2017.

Leandro Londero da Silva: Graduado em Física. Doutor em Educação pela UNICAMP/SP. Tenho dedicado meus estudos e pesquisas na área da Educação em Física. Sou Prof. Assistente Doutor do Departamento de Educação do Instituto de Biociências, Letras e Ciências Exatas da UNESP, em São José do Rio Preto. Orientador de Mestrado e Doutorado no Programa de Pós-Graduação em Educação para a Ciência, da Faculdade de Ciências, da UNESP/Bauru e de mestrado no Programa de Pós-graduação em Ensino e Processos Formativos do Instituto de Biociências, Letras e Ciências Exatas da UNESP, em São José do Rio Preto.

E-mail: leandrolondero@gmail.com 


\section{ANEXO 1}

Tabela Energética Quark-Tzee ou General das Partículas - Algumas combinações possíveis. Disponível em: http://ippog.org/sites/ippog.web.cern.ch/files/import/quark_tzee_dicegame.pdf

\begin{tabular}{|c|c|c|c|c|c|}
\hline \multicolumn{4}{|c|}{ Cores primárias (quarks) } & \multirow[b]{2}{*}{ G } & \\
\hline Vermelho (R) & Verde $(G)$ & \multicolumn{2}{|c|}{ Azul (B) } & & \\
\hline \multicolumn{4}{|c|}{ Cores secundárias (antiquarks) } & \multicolumn{2}{|c|}{ Mésons (quark + antiquark) } \\
\hline Ciano $(\mathrm{R})$ & \multicolumn{3}{|c|}{ Magenta $(\mathrm{G})$} & \multicolumn{2}{|c|}{ Vermelho (R) + Ciano (R) } \\
\hline \multicolumn{3}{|c|}{ Bárions (3 quaks) } & & \multicolumn{2}{|c|}{ Verde $(\mathrm{G})+$ Magenta $(\mathrm{G})$} \\
\hline \multicolumn{4}{|c|}{ Vermelho (R) + Verde (G) + Azul (B) } & \multicolumn{2}{|c|}{ Azul (B) + Amarelo (B) } \\
\hline Méson & \multicolumn{2}{|c|}{ Nome } & Estrutura & Massa $\left(\mathrm{Mev} / \mathrm{c}^{2}\right)$ & Pontos \\
\hline$\pi^{+}$ & \multicolumn{2}{|c|}{ Píon } & $\mathrm{ud}$ & 139,6 & \\
\hline$\kappa^{+}$ & \multicolumn{2}{|c|}{ Kaon mais } & us & 493,7 & \\
\hline$\kappa^{0}$ & \multicolumn{2}{|c|}{ Kaon menos } & ds & 497,7 & \\
\hline $\mathrm{P}$ & \multicolumn{2}{|c|}{ Ro } & uu ou dd & 770 & \\
\hline$\phi$ & \multicolumn{2}{|c|}{ Phi } & SS & 1020 & \\
\hline $\mathrm{D}^{0}$ & \multicolumn{2}{|c|}{ D zero } & $\mathrm{cu}$ & 1869 & \\
\hline $\mathrm{D}^{+}$ & \multicolumn{2}{|c|}{ D mais } & $\mathrm{cd}$ & 1869 & \\
\hline $\mathrm{D}_{\mathrm{s}}^{+}$ & \multicolumn{2}{|c|}{ D mais $\mathrm{s}$} & cs & 1968 & \\
\hline $\mathrm{J} / \psi$ & Jota & & $\mathrm{cc}$ & 3097 & \\
\hline $\mathrm{B}^{-}$ & $\mathrm{B}$ me & & $\mathrm{bu}$ & 5297 & \\
\hline $\mathrm{B}^{0}$ & $\mathrm{~B}$ ze & & $\mathrm{db}$ & 5297 & \\
\hline $\mathrm{B}^{0} \mathrm{~s}$ & B zel & & $\mathrm{sb}$ & 5366 & \\
\hline $\mathrm{B}^{+} \mathrm{C}$ & $\mathrm{B} \mathrm{ma}$ & & $\mathrm{cb}$ & 6277 & \\
\hline$\Upsilon$ & Upsi & & $\mathrm{bb}$ & 9460 & \\
\hline Bárion & Nor & & Estrutura & Massa (Mev/c2) & \\
\hline $\mathrm{P}$ & Prót & & uud & 938,3 & \\
\hline $\mathrm{H}$ & Nêut & & udd & 939,6 & \\
\hline$\Lambda^{0}$ & Lambd & & uds & 1116 & \\
\hline$\Sigma^{0}$ & Sigma & & uus & 1189 & \\
\hline$\Sigma^{-}$ & Sigma me & s um & dds & 1197 & \\
\hline$\Delta$ & Delta me & s um & ddd & 1232 & \\
\hline$\Xi^{0}$ & Ksi z & & uss & 1351 & \\
\hline$\Xi^{-}$ & Ksi men & um & dss & 1351 & \\
\hline$\Omega^{-}$ & Ômega m & ss um & Sss & 1672 & \\
\hline$\Lambda_{\mathrm{C}}^{+}$ & Lambda & ais c & udc & 2281 & \\
\hline$\Sigma^{+} \mathrm{C}^{+}$ & Sigma ma & nais c & uuc & 2455 & \\
\hline$\Xi^{+} \mathrm{C}$ & Ksi m & & usc & 2468 & \\
\hline$\Omega_{\mathrm{C}}^{0}$ & Ômega & $\mathrm{O} \mathrm{c}$ & ssc & 2695 & \\
\hline$\Lambda^{0}$ & Lambda & ro b & $\mathrm{udb}$ & 5620 & \\
\hline
\end{tabular}

